\title{
Diagnosis of arrhythmogenic right ventricular cardiomyopathy
}

\author{
Matthew N. Peters, MD, Morgan J. Katz, MD, and Mohi E. Alkadri, MD
}

Arrhythmogenic right ventricular cardiomyopathy (ARVC) is an infrequently diagnosed condition with a high incidence of sudden cardiac death. While the only option for cure is orthotopic cardiac transplantation, the use of an implantable cardiac defibrillator can be life saving. Accordingly, the prompt recognition of ARVC is crucial. Fortunately, a definitive diagnosis of ARVC can often be made by a combination of the clinical history and electrocardiogram alone, as illustrated by the present case. In our patient, who presented with multiple syncopal episodes and in whom ventricular tachycardia was observed shortly after her admission to the emergency department, a lengthy and expensive workup was initiated, which ultimately may have delayed implantation of an implantable cardiac defibrillator. Clinicians should be made aware of the clinical guidelines for dealing with this potentially dangerous condition so that appropriate therapy can be promptly initiated.

W e report the case of a woman who presented to our emergency department with multiple syncopal episodes. She was subsequently found to have arrhythmogenic right ventricular cardiomyopathy (ARVC), an infrequently diagnosed condition with a high incidence of sudden cardiac death (SCD). Our case highlights how ARVC can be rapidly diagnosed with a combination of clinical history and an electrocardiogram (ECG), avoiding a lengthy and expensive diagnostic workup.

\section{CASE REPORT}

A 62-year-old woman with no prior cardiac history presented with a several-week history of recurrent palpitations and near syncope. She reported taking no medications and denied any relevant cardiac family history. Two weeks prior to her current visit, she had been seen for similar complaints and had an extensive diagnostic workup that included blood chemistry testing, ECG, exercise stress echocardiography, and a computed tomography scan on a pulmonary embolism protocol. Despite a completely negative diagnostic workup, the patient's symptoms continued to increase in frequency and duration.

Upon presentation to the emergency department, the patient was found to have multiple episodes of a wide-complex tachycardia at a rate of 150 beats per minute, which was noted on telemetry. Baseline ECG revealed a right bundle branch block, inverted $\mathrm{T}$ waves in the anterior precordial leads, and epsilon waves (low amplitude signals between the end of the QRS complexes and the onset of the T waves; see arrows) (Figure 1). Subsequent ECGs documented a monomorphic wide QRS complex tachycardia suggestive of ventricular tachycardia (VT) with left bundle branch morphology and superior axis (Figure 2). Given the combination of the patient's clinical presentation and ECG findings, ARVC was suspected. Subsequent cardiac magnetic resonance imaging revealed areas of right ventricular free wall microaneurysms and wall motion abnormalities with corresponding late gadolinium enhancement, also suggestive of ARVC.

The following day, the patient was brought to the electrophysiology lab, where VT was easily inducible. Following endocardial mapping of the arrhythmia, radiofrequency ablation was applied to 13 sites near the right ventricular apex, and VT was no longer inducible at the end of the procedure. Over the next 48 hours, the patient remained asymptomatic, and no further episodes of VT were seen on the monitor. The patient was sent home but returned to the hospital less than 1 week later complaining of multiple episodes of near syncope and was found to have recurrent VT. The following day the patient was taken to the electrophysiology lab for implantable cardiac defibrillator (ICD) placement. Six months later, the patient has experienced no recurrence of syncope or presyncopal episodes.

\section{DISCUSSION}

ARVC was first described in 1977, and the clinical manifestations include recurrent ventricular arrhythmias, right ventricular failure, and SCD (1). The prevalence of ARVC is estimated to be between 1 in 2000 and 1 in 5000, and it can be inherited in both autosomal dominant and autosomal recessive patterns $(2,3)$. ARVC is three times more common in women, and the average age of onset of clinical symptoms is 29 (3). While ARVC accounts for up to $11 \%$ of all cases of SCD in Italy (22\% of SCD in athletes), it is rarely diagnosed in the United States,

From the Department of Internal Medicine, Tulane University Health Sciences Center, New Orleans, Louisiana (Peters, Katz); and the Department of Cardiology, Ochsner Medical Center, Jefferson, Louisiana (Alkadri).

Corresponding author: Matthew N. Peters, MD, 3700 Orleans Avenue, Apartment 3201, New Orleans, Louisiana 70119 (e-mail: mattpeters25@gmail.com). 


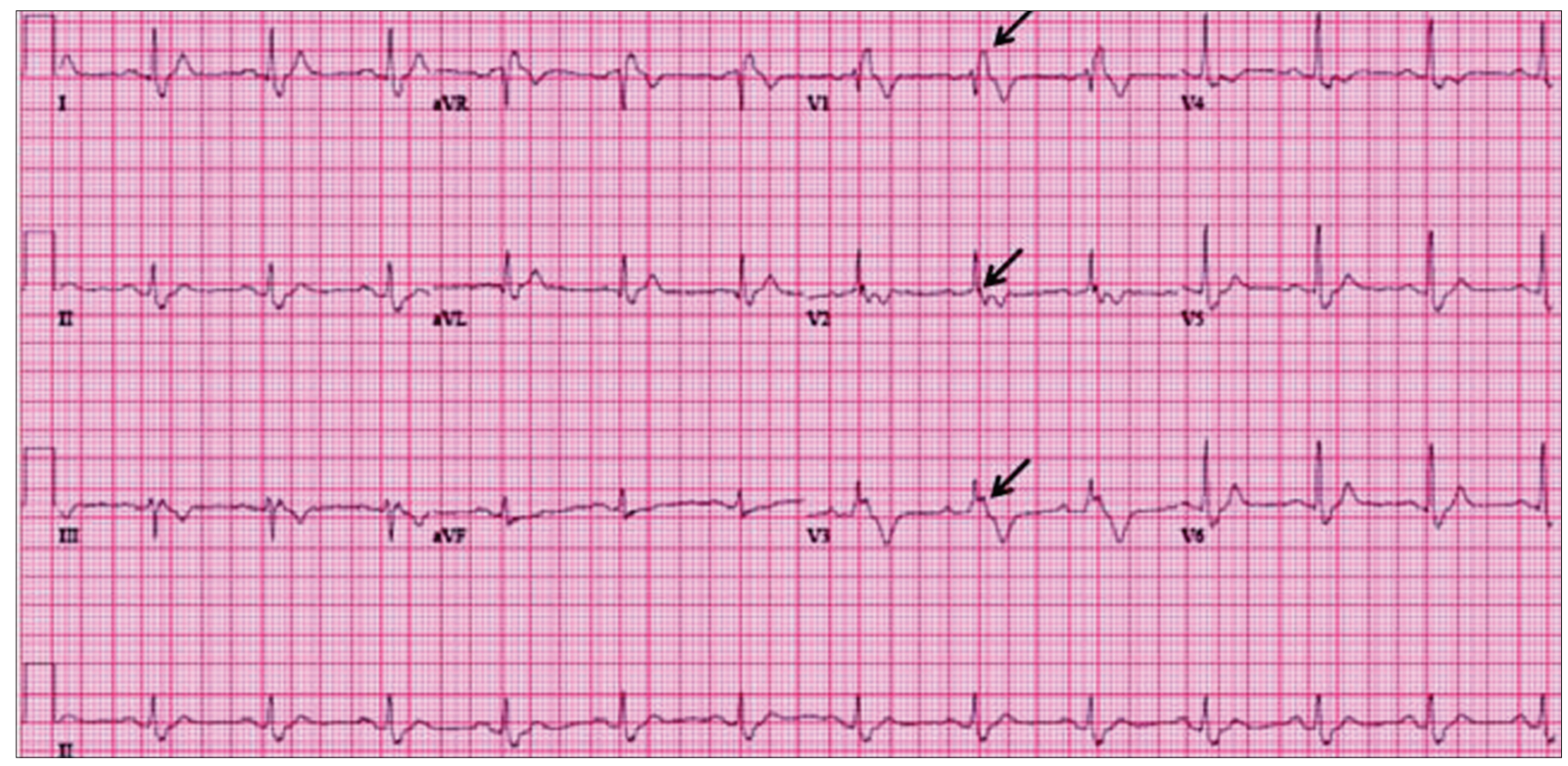

Figure 1. Admission baseline electrocardiogram revealing the presence of inverted T waves and epsilon waves (black arrows) in the right precordial leads and right bundle branch block. The presence of epsilon waves is a major criterion for diagnosis of arrhythmogenic right ventricular cardiomyopathy according to the 2010 proposed modification of task force criteria (5). The presence of inverted T waves in the right precordial leads in patients older than 15 would also be a major criterion, except for the presence of right bundle branch block (5).

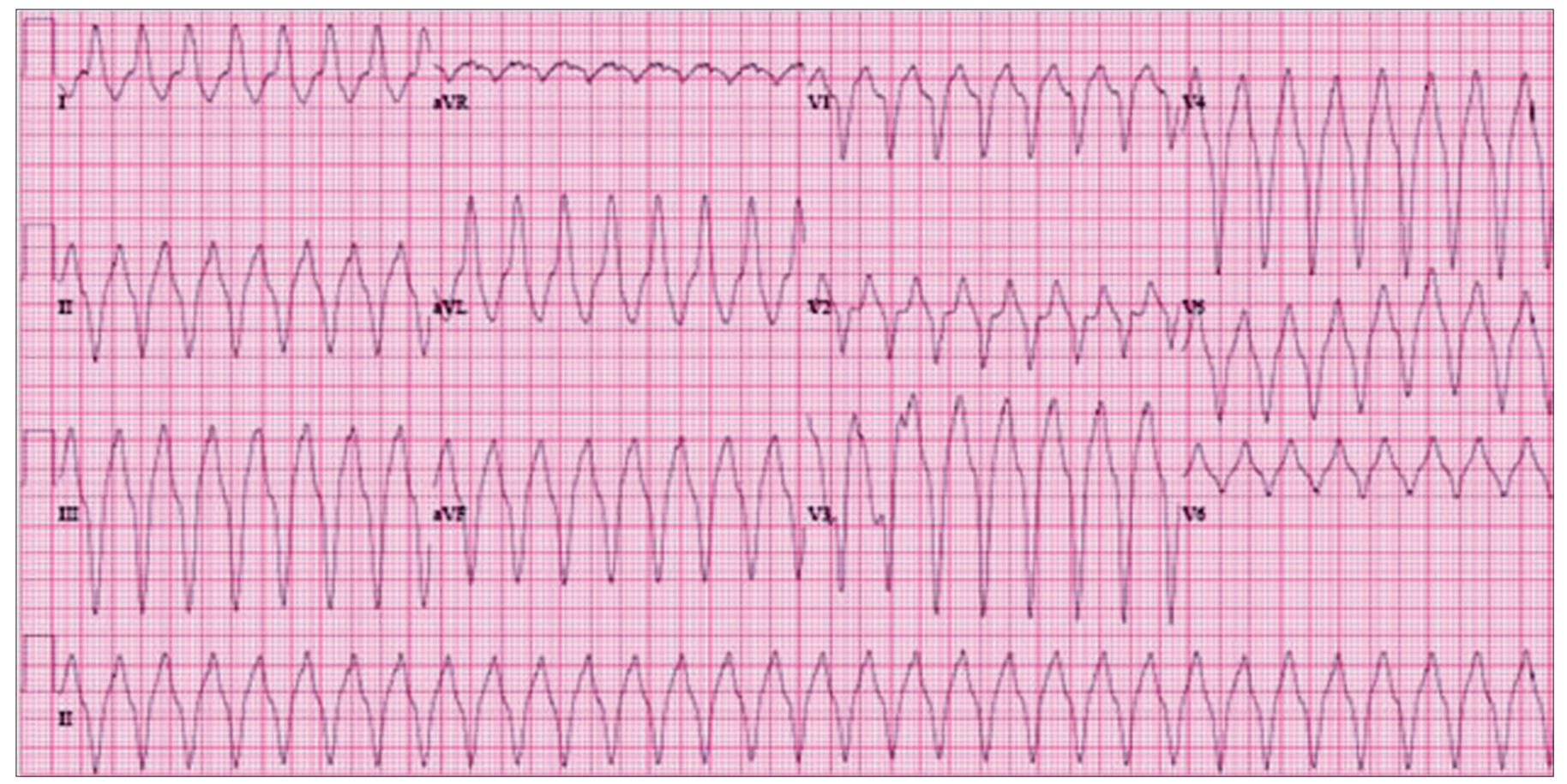

Figure 2. Admission electrocardiogram demonstrating a monomorphic wide QRS complex tachycardia at a rate of 190 beats per minute, suggestive of ventricular tachycardia with left bundle branch morphology and superior axis. Ventricular tachycardia with left bundle branch block morphology and superior axis are major criteria for diagnosis of arrhythmogenic right ventricular cardiomyopathy according to the 2010 proposed modification of task force criteria (5).

possibly due to underdiagnosis (2). SCD is the third most common presenting symptom (behind syncope and palpitations) and is the initial symptom in $23 \%$ of cases (4). Consequently, an increased awareness and prompt recognition of ARVC has considerable life-saving potential.
In 2010, Marcus et al published a proposed modification of the task force criteria for the diagnosis of arrhythmogenic right ventricular cardiomyopathy/dysplasia (revising previously established 1994 criteria) (5). In the 2010 modification, there are six major categories, divided into major and minor criteria 

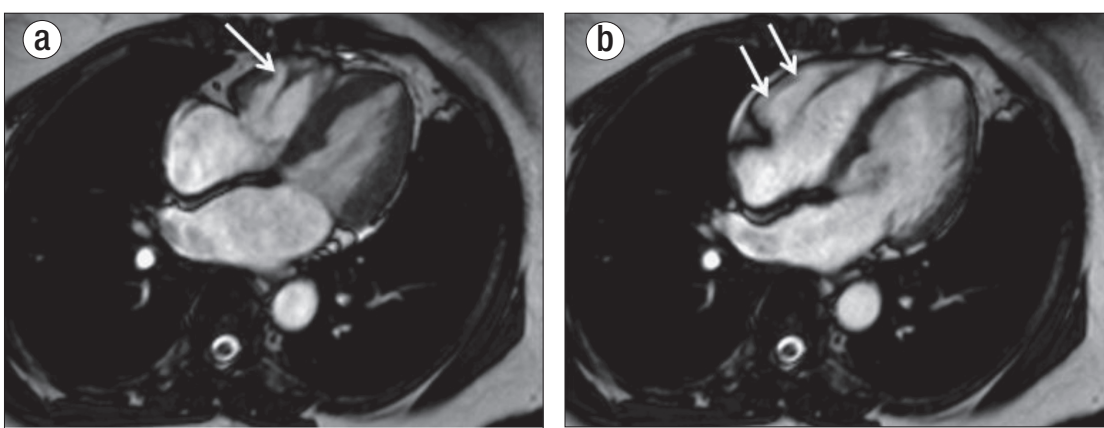

Figure 3. Cardiac magnetic resonance images in frames from horizontal long-axis cine sequence showing (a) end systole with irregular silhouette of the free right ventricular wall due to microaneurysms (arrow) and (b) end diastole showing late gadolinium enhancement (arrows). Regional right ventricular akinesia, dyskinesia, or aneurysm are major criteria for diagnosis of arrhythmogenic right ventricular cardiomyopathy according to the 2010 proposed modification of task force criteria (5).

(Table) (5). Based on these criteria, the diagnosis can be stratified as definitive with fulfillment of as few as two major or one major and two minor criteria (5). Utilizing these criteria, it may be possible to avoid further diagnostic studies that can be both invasive and expensive. For example, right ventricular biopsy has traditionally been used as a confirmatory test in ARVC. However, due to the patchy distribution of the fibrosis and the fact that intramyocardial fat often occurs in anterolateral and apical regions of the heart in normal individuals, there is a fairly high incidence of both false-positives and false-negatives (6). Similarly, while cardiac magnetic resonance allows for the identification of global and regional ventricular dilation, the presence of intramyocardial fat, focal wall thinning, and the occurrence of late gadolinium enhancement, it has the disadvantage of a high false-positive rate and considerable interobserver variability (7). In contrast, echocardiography, which is considerably cheaper, has been shown to have a diagnostic specificity as high as $95 \%$ (8). Thus, we propose that cardiac magnetic resonance may be more useful when the clinical suspicion is high but when neither the ECG nor echocardiographic findings are definitive, as might occur early in the disease process or with family members of affected patients.

Treatment of ARVC has remained disappointing, as the only curative option is orthotopic cardiac transplantation, which is considered only in individuals with progressive heart failure or intractable ventricular arrhythmia. Radiofrequency ablation has proven largely palliative in that it may eradicate some arrhythmogenic foci but the patchy and progressive nature of the disease almost invariably causes new foci to emerge (9). Accordingly, radiofrequency ablation is currently reserved for patients who experience frequent ventricular arrhythmias (and ICD shocks) despite optimal therapy with both ICDs and antiarrhythmic medication (10). It should be noted, however, that the role of radiofrequency ablation may continue to increase in the future, as mapping techniques continue to evolve.

Currently, the 2006 guidelines from the American College of Cardiology, American Heart Association, and European Society of Cardiology recommend ICD implantation for secondary prevention in all patients with prior sustained VT or ventricular fibrillation and for primary prevention in a selected high-risk group of patients (11). This high-risk group includes patients with extensive disease, those with a family history of SCD, and young patients, as evidenced by a decrease in the odds ratio (0.77) for SCD for every 5 years of age (4, 11). Following ICD implantation, adjunctive therapy with antiarrhythmic drugs, especially sotalol and amiodarone, is often employed to prevent subsequent ICD shocks (11).

While ICDs are currently the first-line treatment option for ARVC, several issues can render ICDs both less effective and potentially riskier than in individuals with other types of heart disease. The 2006 guidelines note that fibrofatty changes in the right ventricle of ARVC patients may interfere with adequate lead positioning and arrhythmia sensing (11). Additionally, patients with ARVC often have thin right ventricular walls that can predispose them to perforation, a risk that becomes even greater when considering that multiple ICD lead replacements may be necessary, given the relatively young age of onset typical of ARVC (11).

Attention should also be focused on identification of ARVC in associated family members. Twelve types of ARVC have been identified and mapped to mutations in different chromosomes, leading to defective cell adhesion and myocardial sarcoplasmic reticulum calcium release (12). All 12 types of ARVC can be inherited in an autosomal dominant fashion. Consequently, ARVC has proved to be familial in $30 \%$ of cases (13). Accordingly, it is currently recommended that family members of ARVC patients abstain from high-intensity activity until adequate genetic screening can be carried out.

1. Gemayel C, Pelliccia A, Thompson PD. Arrhythmogenic right ventricular cardiomyopathy. J Am Coll Cardiol 2001;38(7):1773-1781.

2. Dalal D, Nasir K, Bomma C, Prakasa K, Tandri H, Piccini J, Roguin A, Tichnell C, James C, Russel SD, Judge DP, Abraham T, Spevak PJ, Bluemke DA, Calkins H. Arrhythmogenic right ventricular dysplasia: a United States experience. Circulation 2005;112(25):3823-3832.

3. Corrado D, Thiene GC. Arrhythmogenic right ventricular cardiomyopathy/dysplasia: clinical impact of molecular genetic studies. Circulation 2006;113(13):1634-1647.

4. Azaouagh A, Churzidse S, Konorza T, Erbel R. Arrhythmogenic right ventricular cardiomyopathy/dysplasia: a review and update. Clin Res Cardiol 2011;100(5):383-394.

5. Marcus FI, McKenna WJ, Sherrill D, Basso C, Bauce B, Bluemke DA, Calkins H, Corrado D, Cox MG, Daubert JP, Fontaine G, Gear K, Hauer R, Nava A, Picard MH, Protonotarios N, Saffitz JE, Sanborn DM, Steinberg JS, Tandri H, Thiene G, Towbin JA, Tsatsopoulou A, Wichter T, Zareba W. Diagnosis of arrhythmogenic right ventricular cardiomyopathy/ dysplasia: proposed modification of the task force criteria. Circulation 2010;121(13):1533-1541.

6. Basso C, Thiene G. Adipositas cordis, fatty infiltration of the right ventricle, and arrhythmogenic right ventricular cardiomyopathy. Just a matter of fat? Cardiovasc Pathol 2005;14(1):37-41.

7. Azaouagh A, Churzidse S, Konorza T, Erbel R. Arrhythmogenic right ventricular cardiomyopathy/dysplasia: a review and update. Clin Res Cardiol 2011;100(5):383-394.

8. Basso C, Corrado D, Marcus FI, Nava A, Thiene G. Arrhythmogenic right ventricular cardiomyopathy. Lancet 2009;373(9671):1289-1300. 
Table. Proposed modification of criteria for diagnosis of arrhythmogenic right ventricular cardiomyopathy/dysplasia*

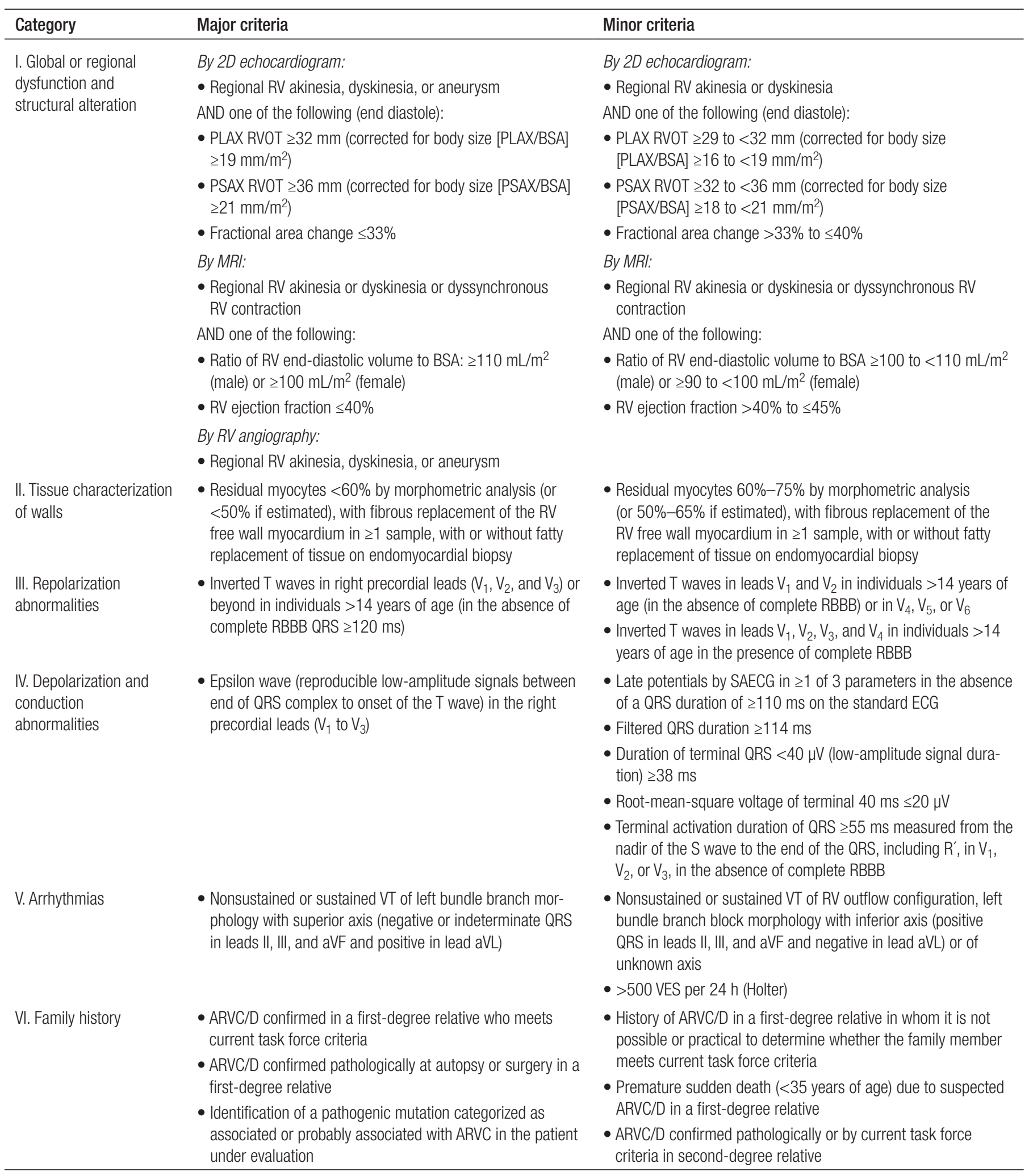

*From Marcus et al, 2010 (5). Used with permission from Oxford University Press.

ARVC/D indicates arrhythmogenic right ventricular cardiomyopathy/dysplasia; aVF, augmented voltage unipolar left foot lead; aVL, augmented voltage unipolar left arm lead; BSA, body surface area; ECG, electrocardiogram; LV, left ventricle; MRI, magnetic resonance imaging; PLAX, parasternal long axis view; PSAX, parasternal short axis view; RBBB, right bundle branch block; RV, right ventricle; RVOT, RV outflow tract; SAECG, signal-averaged electrocardiography; VES, ventricular extrasystole; VT, ventricular tachycardia. 
9. Dalal D, Jain R, Tandri H, Dong J, Eid SM, Prakasa K, Tichnell C, James C, Abraham T, Russell SD, Sinha S, Judge DP, Bluemke DA, Marine JE, Calkins H. Long-term efficacy of catheter ablation of ventricular tachycardia in patients with arrhythmogenic right ventricular dysplasia/ cardiomyopathy. J Am Coll Cardiol 2007;50(5):432-440.

10. Corrado D, Calkins H, Link MS, Leoni L, Favale S, Bevilacqua M, Basso C, Ward D, Boriani G, Ricci R, Piccini JP, Dalal D, Santini M, Buja G, Iliceto S, Estes NA 3rd, Wichter T, McKenna WJ, Thiene G, Marcus Fl. Prophylactic implantable defibrillator in patients with arrhythmogenic right ventricular cardiomyopathy/dysplasia and no prior ventricular fibrillation or sustained ventricular tachycardia. Circulation 2010;122(12):1144-1152.

11. European Heart Rhythm Association; Heart Rhythm Society, Zipes DP, Camm AJ, Borggrefe M, Buxton AE, Chaitman B, Fromer M, Gregoratos G, Klein G, Moss AJ, Myerburg RJ, Priori SG, Quinones MA, Roden DM, Silka MJ, Tracy C, Smith SC Jr, Jacobs AK, Adams CD, Antman EM, Anderson JL, Hunt SA, Halperin JL, Nishimura R, Ornato JP, Page RL, Riegel B, Priori SG, Blanc JJ, Budaj A, Camm AJ, Dean V, Deckers
JW, Despres C, Dickstein K, Lekakis J, McGregor K, Metra M, Morais J, Osterspey A, Tamargo JL, Zamorano JL. ACC/AHA/ESC 2006 guidelines for management of patients with ventricular arrhythmias and the prevention of sudden cardiac death: a report of the American College of Cardiology/American Heart Association Task Force and the European Society of Cardiology Committee for Practice Guidelines. J Am Coll Cardiol 2006;48(5):e247-e346.

12. Bauce B, Nava A, Beffagna G, Basso C, Lorenzon A, Smaniotto G, De Bortoli M, Rigato I, Mazzotti E, Steriotis A, Marra MP, Towbin JA, Thiene G, Danieli GA, Rampazzo A. Multiple mutations in desmosomal proteins encoding genes in arrhythmogenic right ventricular cardiomyopathy/ dysplasia. Heart Rhythm 2010;7(1):22-29.

13. Hodgkinson KA, Parfrey PS, Bassett AS, Kupprion C, Drenckhahn J, Norman MW, Thierfelder L, Stuckless SN, Dicks EL, McKenna WJ, Connors SP. The impact of implantable cardioverter-defibrillator therapy on survival in autosomal-dominant arrhythmogenic right ventricular cardiomyopathy (ARVD5). J Am Coll Cardiol 2005;45(3):400-408.

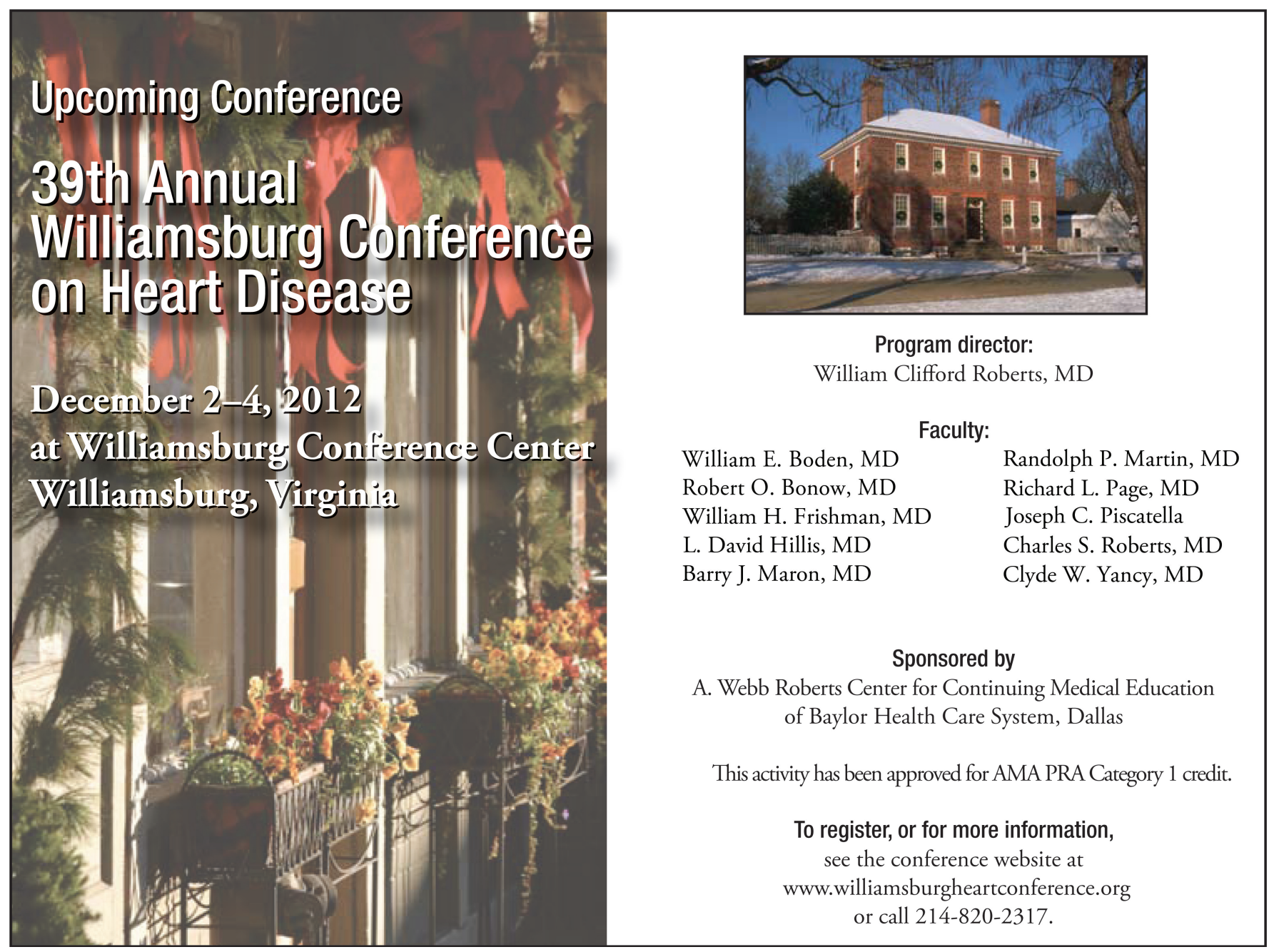

